\title{
Sublingual versus vaginal use of Misoprostol for induction of labor
}

\author{
Mamta Bansal, Indu Sharma*, Jyoti Lagoo, Harish Jadhav
}

Department of Obstetrics and Gynecology, Late BRKM Government Medical College, Dimrapal, Jagdalpur, Bastar, Chhattisgarh, India

Received: 22 September 2019

Accepted: 31 October 2019

\section{*Correspondence:}

Dr. Indu Sharma,

E-mail: georgian.indu@gmail.com

Copyright: (C) the author(s), publisher and licensee Medip Academy. This is an open-access article distributed under the terms of the Creative Commons Attribution Non-Commercial License, which permits unrestricted non-commercial use, distribution, and reproduction in any medium, provided the original work is properly cited.

\section{ABSTRACT}

Background: Induction of labor is one of the great challenges for obstetric care provider. Misoprostol is used for induction of labor by various routes with the advantages in being cheap and stable at room temperature and widely available even in resource-poor settings.

Methods: A randomized controlled study was conducted in the obstetrics and gynecology department of Govt. Medical College and associated Maharani Hospital, Bastar, Chhattisgarh, India over a period of 1.75 years from September 2014 to May 2016. Study has comprised of 200 pregnant women admitted in the department for induction of labor fulfilling the inclusion and exclusion criteria. Data was collected and analyzed by SPSS 16.0. z-test and chisquare test to compare the safety and efficacy of both the routes of misoprostol use for IOL.

Results: There were insignificant differences in number of doses required for induction with satisfactory maternal and neonatal outcome but shorter (12 hours) induction delivery interval with sublingual Misoprostol induction. Most of the cases of both the groups were delivered by vaginal route $(86 \%$ and $62 \%)$ within 12 hours of induction $(58 \%$ and $42 \%$ ) yet significant ( $\mathrm{p}$ value $<0.001$ ) number of cases had undergone caesarean in group of vaginal misoprostol administration (29\%) with major indications of meconium stained liquor (3\% and 12\%) and non assuring fetal heart rate $(1 \%$ and $10 \%)$.

Conclusions: Although both the routes of induction by Misoprostol are well tolerated by the women with satisfactory neonatal outcome, sublingual Misoprostol has an added advantage of quicker delivery, less caesarean and ease of administration indicates better safety and effectiveness.

Keywords: Effectiveness, Induction of labor, Misoprostol, Safety, Sublingual, Vaginal

\section{INTRODUCTION}

Induction of labor is defined as the process of artificially stimulating the uterus to start labor. Obstetrician recommends the use of induction of labor in circumstances in which the risks of waiting for the onset of spontaneous labor are greater than the risks associated with shortening the duration of pregnancy by induction. Induction of labor is one of the great challenges in obstetric care. High risks of both maternal as well as fetal complications are related to induction of labor. Recent published data of expectant management versus induction of labor shows that there is, a significantly elevated risk for caesarean section (CS) in full time induced pregnancies, even after controlling for suspected confounders. ${ }^{1-4}$

Misoprostol is a prostaglandin E1 analogue, developed for the treatment and prevention of gastric ulcers. Its proven efficacy of uterine contractility and cervical ripening has led to a drug currently being used for termination of unwanted pregnancy, management of 
incomplete and spontaneous abortions, induction of labor, augmentation of labor, and treatment of postpartum hemorrhage (PPH). ${ }^{4}$ Misoprostol has advantages in being cheap and stable at room temperature and widely available also in most resource-poor settings. Misoprostol is included in the World Health Organization (WHO) essential medicine list on several indications including labor induction. ${ }^{4}$ Misoprostol has been widely studied in a variety of dosages and routes of administration as an alternative to oxytocin. Misoprostol offers the advantage of promoting both cervical ripening and myometrial contractility. ${ }^{5}$

Success of induction of labor depends on cervical ripening. Various methods are available for induction of labor but the search for the ideal agent, timing, and dosage interval to convert an unfavourable cervix to one receptive to delivery is an ongoing process. Attention has been focused on prostaglandins as effective pharmacological adjuncts to induction.

Sublingual and vaginal routes have prolonged activity and possess the greatest bioavailability. ${ }^{6}$ Benefits of the sublingual route might include less frequent need for vaginal examinations, greater freedom of position in the labor bed, and ease of administration. ${ }^{7}$

The aim of this study is to compare the previously used vaginal administration of Misoprostol with sublingual administration for labor induction regarding induction delivery interval, maternal and neonatal outcome.

\section{METHODS}

A randomized controlled study was conducted in the obstetrics and gynecology department of Govt. Medical College and Associated Maharani Hospital, Bastar, Chhattisgarh, India over a period of 1.75 years from September 2014 to May 2016. The study population was 200 cases of all pregnant women near term fulfilling the inclusion and exclusion criteria. These cases were randomly divided into 2 groups. 100 cases of group A were induced by sublingual $25 \mu \mathrm{g}$ Misoprostol while other 100 cases of group B were induced by $25 \mu \mathrm{g}$ per vaginal Misoprostol after informed consent. Misoprostol administration was repeated every 4 hourly after assessment if needed.

\section{Inclusion criteria}

- Singleton pregnancy

- Cephalic presentation

- Gestational age $\geq 37$ weeks

- Reactive foetal heart pattern

- $\quad$ Bishop score of $<6$

- Intact or early rupture of membranes (less than 6 hours).

\section{Exclusion criteria}

- Malpresentations

- Previous uterine scar

- Placenta praevia, vasa praevia, active genital herpes

- Contracted pelvis and cephalopelvic disproportion

- Pelvic tumours

- $\quad$ Severe medical illness such as asthma, heart disease.

\section{The indications for induction}

- Premature rupture of membrane

- Hypertensive disorders of pregnancy i.e preeclampsia, eclampsia

- Post-dated pregnancy

- Oligohydramnios

- Foetal growth restriction

- Maternal medical illness requiring termination like DM, chronic hypertension

- Intrauterine foetal death.

Progress of labour was monitored by maintaining partograph along with clinical monitoring of Bishops score every time before giving Misoprostol, foetal heart rate and uterine contractions. Any deviation from normal was dealt with, as and when required accordingly. All cases were closely watched.

Important outcomes regarding induction to delivery interval, mode of delivery (vaginal, instrumental, caesarean), successful induction (4-5 cm of cervical dilatation with effective uterine contractions within 4 hours of last dose of Misoprostol), foetal heart rate variation, indication for caesarean section, number of Misoprostol doses, dysfunctional uterine action (hyper stimulation and tachysystole) and Misoprostol related side effects (nausea, vomiting, fever, shivering, headache, diarrhoea) were noted. Neonatal outcome in terms Apgar score at one and five minutes, passage of meconium, cause of NICU admission and neonatal mortality, if any. Tachysystole was defined as six or more uterine contractions in 10 minutes. Uterine hyper stimulation was defined as tachysystole associated with abnormal foetal heart pattern.

\section{Statistical analysis}

Statistical analysis of the data is carried out using statistical packages for SPSS 16.0 for Windows (SPSS Inc., Chicago, IL, USA). Continuous and categorical variables are expressed as mean $\pm \mathrm{SD}$ and percentages, respectively. $\mathrm{Z}$ test for proportion and $\mathrm{Chi}$ - square test is applied to compare between two categorical data. Students t-test is applied to compare between the two continuous data. $\mathrm{p}<0.5$ was considered statistically significant. 


\section{RESULTS}

200 pregnant women admitted in the department for induction of labour were randomly divided into 2 groups of 100 cases in each group. In 100 cases $25 \mathrm{mcg}$ Misoprostol was given sublingually labelled as Group A and other 100 cases were given $25 \mathrm{mcg}$ Misoprostol per vaginally labelled as Group B. These 2 groups were compared and following results were obtained.

Table 1: Demographic variables of both the groups.

\begin{tabular}{|llll|}
\hline Variables & Group A & Group B & p value \\
\hline Maternal age & $23.47 \pm 3.32$ & $23.55 \pm 3.68$ & 0.86 \\
\hline Parity & $1.36 \pm 0.79$ & $1.54 \pm 0.23$ & 0.24 \\
\hline Gestational age & $39.95 \pm 2.04$ & $40.33 \pm 2.14$ & 0.19 \\
\hline Bishop score & $3.66 \pm 1.1$ & $3.79 \pm 0.83$ & 0.35 \\
\hline
\end{tabular}

Independent $\mathrm{t}$ test, $\mathrm{p}>0.05$; not significant.

Table 2: Demographic variables of both the groups.

\begin{tabular}{|llll|}
\hline $\begin{array}{l}\text { Indications of } \\
\text { induction }\end{array}$ & Group A & Group B & $\begin{array}{l}\text { p } \\
\text { value }\end{array}$ \\
\hline PROM & $40(40 \%)$ & $33(33 \%)$ & 0.30 \\
\hline Post-dated pregnancy & $37(37 \%)$ & $37(37 \%)$ & 1.0 \\
\hline Preeclampsia & $12(12 \%)$ & $13(13 \%)$ & 0.83 \\
\hline Eclampsia & $1(1 \%)$ & $3(3 \%)$ & 0.312 \\
\hline IUGR & $3(3 \%)$ & $7(7 \%)$ & 0.193 \\
\hline Oligohydramnios & $2(2 \%)$ & $3(3 \%)$ & 0.652 \\
\hline Diabetes type 2 & $0(0 \%)$ & $2(2 \%)$ & 0.155 \\
\hline IUD & $5(5 \%)$ & $2(2 \%)$ & 0.25 \\
\hline
\end{tabular}

$\mathrm{z}$ test for 2 proportions $\mathrm{p}>0.05$; not significant.

There was no significant difference of demographic profiles and indications of induction of the cases of both the groups (Table 1 and Table 2).

Table 3: Outcomes of induction of both the groups.

\begin{tabular}{|c|c|c|c|}
\hline Outcomes & Group A & Group B & p value \\
\hline \multicolumn{4}{|c|}{ Number of doses required } \\
\hline 1 dose & $11(11 \%)$ & $13(13 \%)$ & 0.659 \\
\hline 2 doses & $78(78 \%)$ & $76(76 \%)$ & 0.727 \\
\hline 3 doses & $10(10 \%)$ & $10(10 \%)$ & 1 \\
\hline 4 doses & $1(1 \%)$ & $1(1 \%)$ & 1 \\
\hline \multicolumn{4}{|c|}{ Induction delivery interval } \\
\hline$<12$ hours & $58(58 \%)$ & $42(42 \%)$ & 0.02 \\
\hline 12-24 hours & $26(26 \%)$ & $18(18 \%)$ & 0.17 \\
\hline$>24$ hours & $2(2 \%)$ & $2(2 \%)$ & 1.0 \\
\hline \multicolumn{4}{|c|}{ Mode of delivery } \\
\hline FTND & $86(86 \%)$ & $62(62 \%)$ & $<0.001$ \\
\hline LSCS & $9(9 \%)$ & $29(29 \%)$ & $<0.001$ \\
\hline Vacuum & $4(4 \%)$ & $6(6 \%)$ & 0.515 \\
\hline Forceps & $1(1 \%)$ & $3(3 \%)$ & 0.312 \\
\hline
\end{tabular}

$\mathrm{z}$ test for two proportions, $\mathrm{p}<0.001$ highly significant, $\mathrm{p}<0.05$ significant.
Table 3 showed, there was no significant difference in the doses required for induction but significant number ( $p$ value 0.02 ) of women delivered within 12 hours of induction by sublingual Misoprostol $(58 \%)$ as compared to vaginal route $(42 \%)$. Although most of the cases (148 i.e. $74 \%$ ) were delivered vaginally in both the groups but significant number of cases undergone caesarean among Group B (29\%) i.e. vaginal Misoprostol administration ( $\mathrm{p}$ $<0.001)$.

Table 4: Indications of caesarean.

\begin{tabular}{|llll|}
\hline Indications of caesarean & $\begin{array}{l}\text { Group } \\
\text { Failed Induction }\end{array}$ & $\begin{array}{l}\text { Group } \\
\text { B }\end{array}$ & $\begin{array}{l}\text { p } \\
\text { value }\end{array}$ \\
\hline $\begin{array}{l}\text { Meconium Stained } \\
\text { Liquor (In latent phase) }\end{array}$ & $3(3 \%)$ & $4(4 \%)$ & 0.70 \\
\hline $\begin{array}{l}\text { Non assuring foetal heart } \\
\text { rate }\end{array}$ & $1(1 \%)$ & $12(12 \%)$ & 0.015 \\
\hline Non progress of labour & $2(2 \%)$ & $3(3 \%)$ & 0.65 \\
\hline
\end{tabular}

sz test for two proportions $\mathrm{p}>0.05$; not significant.

In our study, total 38 cases had undergone caesarean. Most of the caesarean (29\%) was done among the cases induced by $25 \mu \mathrm{g}$ of vaginal Misoprostol with the indication of meconium stained liquor (12/100) followed by non-assuring fetal heart (10/100). Significantly higher number of cases were taken for caesarean because of occurrence of MSL in latent phase of labor induced by vaginal route $(12 \%)$ as compared to sublingual route (only 3\%) as well as $10 \%$ fetus of Group B showed non assuring fetal heart rate in comparison to only $1 \%$ in Group A (p 0.015 and 0.005 ). While $4 \%$ cases of group B and only $3 \%$ cases of Group A underwent caesarean for failed induction (Table 4).

Table 5 showed, there was no significant difference of maternal adverse effects of Misoprostol induction whether it was administered by sublingual route or vaginal route ( $p$ value 0.078 ) yet we found more cases of fever and vomiting in Group A while hyperstimulation and tachysystole was seen in cases of Group B.

Table 5: Maternal adverse effects.

\begin{tabular}{|c|c|c|c|}
\hline $\begin{array}{l}\text { Maternal } \\
\text { adverse effects }\end{array}$ & $\begin{array}{l}\text { Group } \\
\text { A }\end{array}$ & $\begin{array}{l}\text { Group } \\
\text { B }\end{array}$ & p Value \\
\hline Fever & $2(2 \%)$ & $1(1 \%)$ & \multirow{4}{*}{$\begin{array}{l}\text { Chi- } \\
\text { square }=6.83 \\
d f=3 \\
p=0.078\end{array}$} \\
\hline Vomiting & $1(1 \%)$ & 0 & \\
\hline Hyperstimulation & 0 & $2(2 \%)$ & \\
\hline Tachysystole & 0 & $4(4 \%)$ & \\
\hline
\end{tabular}

p>0.05 not significant.

We did not find any significant difference in both the groups regarding neonatal outcomes (Table 6) in terms of Apgar score ( $p$ value $0.179,0.703$ ), passage of meconium ( $p$ value 0.744$)$, NICU admissions or neonatal mortality ( $\mathrm{p}$ value 0.722 ). 
Table 6: Neonatal outcome.

\begin{tabular}{|c|c|c|c|c|}
\hline \multicolumn{2}{|c|}{$\begin{array}{l}\text { Neonatal adverse } \\
\text { effects }\end{array}$} & Group A & Group B & p value \\
\hline \multicolumn{2}{|c|}{ Apgar score at $1 \mathrm{~min}$} & $6.84 \pm 1.16$ & $6.57 \pm 1.53$ & 0.179 \\
\hline \multicolumn{2}{|c|}{ Apgar score at $5 \mathrm{~min}$} & $7.27 \pm 0.85$ & $7.21 \pm 1.01$ & 0.743 \\
\hline \multirow{2}{*}{$\begin{array}{l}\text { Passage of } \\
\text { meconium }\end{array}$} & Yes & 20 & 18 & \multirow{2}{*}{0.744} \\
\hline & No & 80 & 82 & \\
\hline \multicolumn{5}{|c|}{ Cause of NICU admission } \\
\hline \multicolumn{2}{|c|}{ Hyperbilirubinemia } & 12 & 14 & \multirow{6}{*}{0.722} \\
\hline \multicolumn{2}{|c|}{ Respiratory distress } & 0 & 3 & \\
\hline \multicolumn{2}{|c|}{$\begin{array}{l}\text { Meconium aspiration } \\
\text { syndrome }\end{array}$} & 2 & 4 & \\
\hline \multicolumn{2}{|c|}{ Septicaemia } & 2 & 3 & \\
\hline \multicolumn{2}{|c|}{ PASPH } & 4 & 4 & \\
\hline \multicolumn{2}{|c|}{ Neonatal mortality } & 1 & 2 & \\
\hline
\end{tabular}

Row 1,2 -independent $t$ test and rest of the rows-s Chi-square test; $p>0.05$ not significant.

\section{DISCUSSION}

The search for the ideal agent, timing, and dosage interval to convert an unfavorable cervix to one receptive to delivery is an ongoing process. Attention has been focused on Misoprostol, a synthetic analogue of prostaglandin E1, widely studied in a variety of dosages and routes of administration. Vaginal route of Misoprostol use is extensively studied but limited literature is available on sublingual route although it is more convenient for the patient and easy in administration. ${ }^{7,8}$ Even in our institute, there was only vaginal use till now. Therefore, this study was conducted to compare the safety, efficacy and tolerability of sublingual versus vaginal Misoprostol for induction of labor at term. In our study both the groups are similar in their demographic profile. Mean age of Group A cases are 23.47 \pm 3.32 and of Group B are 23.55 \pm 3 .68. Most of the cases are in 20-25 years of age in both the groups similar to other study. ${ }^{9}$ Like the study conducted by Sedigheh A et al, their mean gestational age is also not different $(39.95 \pm 2.04$ and $40.33 \pm 2.14, \mathrm{p}$ value 0.19 ). Both the groups have similar pre induction Bishop score (3.66 \pm 1.1 and $3.79 \pm 0.83, \mathrm{p}$ value 0.35$)$ as well as indications of induction. Majority of induction was done for post-datism followed by premature rupture of membrane (PROM). Although most of the cases of PROM were induced by sublingual Misoprostol but this difference was statistically insignificant ( $\mathrm{p}$ value 0.30 ). There was no significant difference in parity too. ${ }^{10-12}$

Our study is similar to other previous studies found no significant difference in the number of doses required for the induction by sublingual or vaginal route..$^{10,13}$ On contrary significantly higher doses are needed for induction by sublingual Misoprostol in the study conducted by Ahmed B et al. ${ }^{12}$ Similar to other studies conducted previously, most of the cases of sublingual group were delivered within 24 hours and statistically significant number of cases of sublingual group delivered within shorter interval i.e. 12 hours as compared to vaginal group (58\% and $42 \%, \mathrm{p} 0.02$ ) possibly due to faster action of sublingual route. ${ }^{14,15}$ Although majority of cases of both the groups ( $86 \%$ and $62 \%$ respectively) were delivered vaginally but still statistically significant number of cases of sublingual group (86\%) were delivered vaginally ( $\mathrm{p}$ value $<0.001$ ) while significant number of cases had undergone caesarean among the cases induced by vaginal Misoprostol (29\% p value < 0.001 ). Sedigheh $\mathrm{A}$ et al, found maximum delivery in both the groups by vaginal route $(84 \%$ and $90 \%$ respectively) but more caesarean delivery in the group of sublingual Misoprostol administration (14\%) as compared to vaginal Misoprostol (10\%) but this difference was not statistically significant. ${ }^{10}$ The result of study of Ahmed B et al and Feitosa FEL et al, showed much higher rate of caesarean in sublingual group. ${ }^{10,12,13}$ Similar to our study instrumental delivery was also higher in vaginal group of Ahmed B et al, study though it was statistically nonsignificant. ${ }^{12}$ Result of our study is similar to the study of Kattan El et al, in relation to more caesarean in vaginal group of Misoprostol although it was insignificant ( $p$ value 0.747 ) with possible reason of variation in sample size. ${ }^{14}$ Higher caesarean rate in vaginal Misoprostol administration group was also seen in the studies of Wing DA et al, i.e. $15 \%$ versus $25 \%$ and Bartusevicius et al, i.e. $12(17 \%)$ and $14(20 \%)$ respectively. ${ }^{16,17}$ This indicates sublingual route is safer as compare to vaginal administration.

Most of the caesarean was done for the indication of meconium stained liquor (3\% and $12 \%$ ) followed by nonassuring foetal heart rate $(1 \%$ and $10 \%)$ in both the groups with significant difference in indication of caesarean ( $\mathrm{p}$ value 0.015 and 0.005 ). Result of our study was supported by Kattan El et al, where 3/25 cases (12\%) of sublingual group and 4/25 cases (16\%) of vaginal group developed foetal distress as well as $12 \%$ and $16 \%$ cases had meconium stained liquor respectively although these differences were not significant. ${ }^{14}$ In the study of Sedigheh A et al, and Zahran et al, fetal distress had the highest frequency. ${ }^{10,15}$ Our study found insignificantly more cases of failed induction and non progress of labor in vaginal group.

No adverse events as a consequence of tachysystole have been reported in Group A for induction of labour. In our study we had $2 \%$ case of hyper stimulation and $4 \%$ case of tachysystole in Group B and no case in Group A. These rates are almost similar to those of Wing DA et al, $1.8 \%$ versus 2.8 and of Fisher SA et al, Shetty A et al, 1.6 versus 7.7 in oral and vaginal group respectively. ${ }^{11,18,19}$ Both cases of hyper stimulation normal vaginally delivered after being treated for hyper stimulation. All cases were managed with left lateral position and oxygen inhalation and further administration of the drug was stopped. As well as there was no significant difference in adverse neonatal outcomes and NICU admissions of both the groups in aspect of Apgar score at 1 and 5 minutes and passage of meconium which was also similar to 
previous studies. ${ }^{15,18,20}$ The reason of higher frequency of uterine hyperstimulation and tachysystole in vaginal group is its higher efficacy and bioavailability because of avoidance of first pass effect of GIT and hepatic enzymes as well as direct effect on cervix and uterus. ${ }^{21,22}$ Studies done previously had similar results regarding no significant difference in safety of mother as well as fetus by vaginal and sublingual administration of Misoprostol. ${ }^{13,14}$ However, the study of Caliskan E et al, showed significant number of women of sublingual group developed tachysystole $(p=0.005)$ than vaginal group with similar neonatal outcomes. ${ }^{23}$

\section{CONCLUSION}

From above study we concluded that use of sublingual or vaginal Misoprostol are similar in favorable maternal and neonatal outcome but sublingual route is preferable in achieving more successful vaginal delivery within short period of induction with minimal failure of induction (Although it was inconclusive due to small sample size). Sublingual administration has an added advantage for the women, particularly to those who were wishing to avoid multiple vaginal administration. Sublingual Misoprostol is an effective alternative to vaginal Misoprostol in induction of labor. More studies and trails are needed to use sublingual Misoprostol in future for induction of labor.

\section{ACKNOWLEDGMENTS}

Authors would like to thank Dr. Alpana Bansal, Head of the department, Dr. Harish Jadhav, Dr. Anuradha, Dr. Kittu Baradia and Dr. Hemant Sharma for their encouragement and support.

Funding: No funding sources

Conflict of interest: None declared

Ethical approval: The study was approved by the Institutional Ethics Committee

\section{REFERENCES}

1. Danilack VA, Triche EW, Dore DD, Muri JH, Phipps MG, Savitz DA. Comparing expectant management and spontaneous labor approaches in studying the effect of labor induction on cesarean delivery. Ann Epidemiol. 2016;26(6):405.e1-411.e1.

2. Davey MA, King J. Caesarean section following induction of labour in uncomplicated first births- a population-based cross-sectional analysis of 42,950 births. BMC Preg Childbirth. 2016;16(1):Article no.92.

3. Vogel JP, West HM, Dowswell T. Titrated oral Misoprostol for augmenting labour to improve maternal and neonatal outcomes. The Cochrane Database Syst Rev. 2013;9:CD010648.

4. Tang J, Kapp N, Dragoman M, de Souza JP. WHO recommendations for Misoprostol use for obstetric and gynecologic indications. Int $\mathrm{J}$ Gynecol Obstet. 2013;121(2):186-9.

5. Sanchez-Ramos L, Kaunitz AM, Wears RL, Delke I, Gaudier FL. Misoprostol for cervical ripening and labor induction: a meta-analysis. Obstet Gynecol. 1997;89:633-42.

6. Muzonzini G, Hofmeyr GJ. Buccal or sublingual Misoprostol for cervical ripening and induction of labour. Cochrane Database Syst Rev. 2004;4:CD004221.

7. Wolf SB, Sanchez-Ramos L, Kaunitz AM. Sublingual Misoprostol for labor induction: a randomized clinical trial. Obstet Gynecol. 2005;105:365-71.

8. Rodney KE. Preinduction cervical assessment. Clin Obstet Gynecol. 2000;43(3):440-6.

9. Acharya I, Thapa S, Chaudhary P. Efficacy and safety of sublingual versus vaginal misoprostol for pre-induction cervical ripening among primigravida. MJSBH. 2018;17(1):18-24.

10. Ayati S, Vahidroodsari F, Farshidi F, Shahabian M, Aghaee MA. vaginal versus sublingual misoprostol for labor induction at term and post term: a randomized prospective study. Iran J Pharm Res. 2014;13(1):299-304.

11. Shetty A, Danilien P, Templeton A. A comparison of oral and vaginal Misoprostol in induction of labor at term. Br J Obstet Gynaecol. 2001;108:218-24.

12. Ahmad B, Shekhar C, Jindal S, Gupta S. Misoprostol for induction of labor: a comparative study of various routes of administration. Int $\mathrm{J}$ Reprod Contracept Obstet Gynecol. 2017;6:4583-8.

13. Feitosa FEL, Sampaio ZS, Alencar CA, Amorim MMR, Passini R. Sublingual versuss vaginal Misoprostol for induction of labor. Int J Gynecol Obst. 2006;94(2):91-5.

14. Kattan El, Eman A, Moety A, Ghada A, AbdEl R, Rahman A. Sublingual versus vaginal Misoprostol for induction of labor in term primi gravidas: a randomized study. J Evidence-Based Women's Health J Society. 2013;3(3):111-4.

15. Zahran KM, Shahin AY, Abdellah MS, Elsayh KI. Sublingual versus vaginal Misoprostol for induction of labor at term: a randomized prospective placebocontrolled study. J Obstet Gynaecol Res. 2009;35:1054-60.

16. Wing DA, Ham D, Paul RH. A comparison of orally administered Misoprostol with vaginally administered Misoprostol for cervical ripening and labour induction. Am J Obst Gynaecol. 1999;180(5):1155-60.

17. Bartusevicius A, Barcaite E, Krikstolaitis R, Gintautas V, Nadisauskiene R. Sublingual compared with vaginal Misoprostol for labour induction at term: a randomized controlled trial. BJOG. 2006;113:1431-7.

18. Wing DA, Paul RH. A comparison of differing dosing regimens of vaginally administered Misoprostol for pre induction cervical ripening and 
labour induction. Am J Obst Gynaecol. 1996;175:158-64.

19. Fisher SA, Mackenzie VP, Davies GAL. Oral versus vaginal Misoprostol for induction of labor: A doubleblind randomized controlled trial. AJOG. 2001;185(4):906-10.

20. Nassar AH, Awwad J, Khalil AM, Abu-Musa A, Mehio G, Usta IM. A randomized comparison of patient satisfaction with vaginal and sublingual Misoprostol for induction of labor at term. BJOG. 2007;114:1215-21.

21. Zieman M, Fong SK, Benowitz NL, Banskter D, Darney PD. Absorption kinetics of Misoprostol with oral or vaginal administration. Obstet Gynecol. 1997;90:88-92.

22. Danielsson KG, Marions L, Rodriguez A, Spur BW, Wong PYK, Bygdeman M. Comparison between oral and vaginal administration of Misoprostol on uterine contractility. Obstet Gynecol. 1999;93:27580.

23. Caliskan E, Bodur H, Ozeren S, Corakci A, Ozkan S, Yucesoy I. Misoprostol $50 \mu \mathrm{g}$ sublingually versus vaginally for labor induction at term: a randomized study. Gynecol Obstet Invest. 2005;59:155-61.

Cite this article as: Bansal M, Sharma I, Lagoo J, Jadhav H. Sublingual versus vaginal use of Misoprostol for Induction of labor. Int J Reprod Contracept Obstet Gynecol 2019;8:4960-5. 